\title{
Analysis and Research on Risk Control and Profitability of Sharing Economy Business Model
}

\author{
Chunxiang $\mathrm{Li}^{1, *, \dagger}{ }^{*}$, Yang Liu ${ }^{2, \dagger}$, Wenyi Peng ${ }^{3, \dagger}$, Ziqi Zhang ${ }^{4, \dagger}$ \\ ${ }^{1}$ Columbia university in the city of New York, New York, NY10027 \\ ${ }^{2}$ The Hong Kong Polytechnic University, Hong Kong, 999077 \\ ${ }^{3}$ Bryant university, Smithfield, Rhode island, 02917 \\ ${ }^{4}$ University of Shanghai for Science and Technology, Shang Hai, 200031 \\ ${ }^{*}$ Corresponding author.Email: cl4143@columbia.edu \\ These authors contributed equally.
}

\begin{abstract}
With the development of the Internet and big data technology, traditional production and consumption models have been challenged, and the "sharing economy" has become a new trend. The sharing of goods, services and information through the network platform using the business model of the sharing economy has attracted more and more attention from the industry and academia. Although the sharing economy is developing rapidly, there are still many competitions and uncertainties in its development. Therefore, it is particularly important to analyze the profitability of the sharing economy business model to identify and avoid busiwatness risks. This article adopts the literature research method, case research method and comparative analysis method to conduct comprehensive analysis from two perspectives of risk management and profitability. We discuss the risks and challenges facing the potential of the sharing economy, the current business model of the shared bicycle industry, and the risk management and profitability issues of the sharing economy business model, propose supplements and improvements to relevant regulations, ensure data transmission security, and formulate antitrust laws to promote Competition, rational application of blockchain technology and other countermeasures to help avoid risks and maximize profitability.
\end{abstract}

Keywords: Sharing economy, Risk management and control, Profitability, Countermeasure.

\section{INTRODUCTION}

With the development of the internet and big data technology, the traditional production and consumption models are being challenged and we are moving towards a collaborative consumption economy [1]. 'Sharing economy', also known as 'collaborative consumption', refers to sharing goods, services and information through online platforms, which is growing rapidly and drawing increasing attention from industries and academics [2]. PwC predicts that the global revenue of sharing economy will increase to $\$ 335$ billion by 2025 [3]. Airbnb and Uber have been placed in the centre of this industry for their successful business models and high profitability [4]. Airbnb provides short term lodging service via online sharing platform which is valued at $\$ 25.5$ billion in 2016 , while Uber is valued at $\$ 62.5$ billion for its ride sharing and pick-up service [5]. China' s sharing economy is also growing significantly. In 2018, the market transaction volume increased by $41.6 \%$ relative to last year, reaching 294.2 billion yuan with about 760 million participants [6]. However, although the market is growing rapidly with proven business models and established companies, firms should not ignore the challenges and uncertainties in this highly competitive industry as demonstrated by the failure and difficulties of some firms in recent years, such as Ofo sharing bicycles in China [2]. Profitability is the core competence of a firm and the foundation of a company's sustainable growth. Risk management is fundamental to the stability of a firm's operation and economic growth. Since the level of profitability of a firm is directly related to its ability to mitigate risks, and risk management also impacts a firm's stable growth and profitability, it is important to explore effective risk management mechanisms and measures to increase profit growth securely and stably.

Hossain in his study found that the highly cited articles related to sharing economy mostly focus on 
participating motivation, customer satisfaction, price setting and impact of sharing economy, while accommodation and transportation are the two major sectors. He also discussed the business and revenue model of sharing economy as well as significant challenges, which would provide valuable reference to our analysis [7]. Similarly, the study by Cheng discovered that the three focuses of research on sharing economy lie in business model and impact, nature and sustainability, while the two major areas are tourism and hospitality [8]. As to study related to business model, research concerning the relationship between customers and firms proposed a profitable business model for sharing economy, which is a double-sided customer framework [9]. However, it did not investigate the associated risks and how to alleviate these risks under the proposed profitable business model. Furthermore, the study by Hong et al. analysed the effectiveness of firms' mechanism to reduce risks and gain profit. The research focused on two perceived risks-: physical risk and performance risk, and two specific measure to mitigate risks: investment to reduce physical risks and word-of-mouth mechanism to alleviate performance risks. As a result, they found that when the risk increases, the firms' safety investment would contribute more to profit growth [4]. However, this study did not review the risks and mitigating measures comprehensively and propose suggestions for increasing future profit growth.

Based on a review of literature in the areas of risks and profitability of sharing economy, we found that most studies focused either on business model and profitability, or on challenges and associated risks. There were few studies combining risk management and profitability and putting forward suggestions of how to mitigate risks and increase profit in the long run. In this case, based on comprehensive analysis of opportunities and challenges of the sharing economy, we have done some exploratory to identify risks and growth opportunities, analyse how to improve profitability under the premise of ensuring safety as well as how to ensure safety based on profit growth.

We conduct comprehensive analysis from two perspectives-risk management and profitability using literature review method, case study and comparative analysis method. Through review of the literature and industry reports, we gained insights into the current business environment of sharing economy, including opportunities and challenges, as well as the characteristics of the business model of firms in the sharing economy, which facilitated our work and process of identifying perceived risks and growth opportunities. We also conduct studies related to specific firms, including firms with successful strategies and stable profitability and firms with failure and difficulties. Combined with comparative analysis method, we compare the financial and operational performance of some typical companies both vertically and horizontally with the aim of finding the underlying reason for its success or failure, thus providing reference to the sharing economy firms as to how to increase its competitiveness. We expect the study to find the critical factors influencing the profitability of sharing economy firms and effective measures to alleviate risks, which would provide comprehensive reference to firms in this industry.

\section{METHOD}

\subsection{Case study method}

The case study method combines market reality, uses typical cases as materials, and through specific analysis and anatomy, to encourage people to enter specific marketing scenarios and marketing processes, establish true marketing feelings, and seek solutions to marketing problems [10]. We focus on shared travel. Because shared travel is the most commonly seen and exposed in people's daily lives in almost all cases. In recent years, companies that promote shared travel have also emerged one after another, represented by Ofo, a model company among them.

We will combine the market reality of the shared travel business model, specifically analyse the operation mode and cost control of one of the representative companies, Ofo, analyse and evaluate its existing risks and profitability, and expand to the possible risks of the entire shared travel model as well as the overall profitability of the industry. we will strive to put forward suggestions on problems, avoid risks, minimize costs and losses, and maximize profits.

\subsection{Qualitative comparative analysis method}

In statistics, qualitative comparative analysis (QCA) is a data analysis based on set theory to examine the relationship of conditions to the outcome. QCA describes the relationship in terms of necessary conditions and sufficient conditions [11].

We will compare the operation modes and profit differences of different companies in the same industry for the sharing economy business model, and summarize the different risks and challenges faced by the sharing economy model within the industry through comparative analysis.

At the same time, we will also compare the application and profitability of sharing business models in different countries and regions, analyse and evaluate the different risks that may exist in the sharing economy based on their differences and summarize the different risks to help us follow Recommendations and summaries for risk control and cost control. 


\subsection{Literature analysis method}

The literature research method is a method to obtain information through investigating literature according to a certain research purpose or topic to fully and correctly understand and master the research problem [12].

Reports on the definition and research categories of the sharing economy can help us understand the history and current status of the sharing business model, help define, understand and analyse the sharing economy, and supplement the risk control and profitability of the sharing business model we are studying. The role of background knowledge.

Papers on some simple economic categories of the sharing economy can help us form a general impression of the sharing business model, help us model the framework of the entire model, and analyse and evaluate this model more specifically.

The papers comparing the results of different case interviews in the sharing economy can help us obtain comparative data of realistic data, and help us compare and analyse the risk issues and profitability of different business models, so as to draw overall conclusions and reasonable suggestions.

The comprehensive literature report on the sharing business model helps us understand the full picture of the sharing business model, thereby deepening our knowledge and understanding of the research topics, helping us to analyse rationally, avoid risks, and maximize profits.

\section{RESULT}

\subsection{Challenges in the potential of the sharing economy}

\subsubsection{Opportunity}

Development status and evolution trend, the current opportunity of enjoying the economy is the industry has begun to take shape, the future potential is huge. At present, the sharing economy in China is developing rapidly, and platform enterprises are growing rapidly. China's Sharing Economy Development Report 2016, completed by the State Information Center, shows that the market size of China's sharing economy in 2015 was about 195.6 billion yuan, mainly concentrated in transportation, short-term housing rental, finance, life services, knowledge and skills, production capacity and other six fields. About 50 million people, or $5.5 \%$ of the total labor force, participate in providing services in the sharing economy. It is conservatively estimated that the total number of people participating in the sharing economy has exceeded 500 million. It is estimated that the sharing economy will grow at an average annual rate of around $40 \%$ in the next five years, and will account for more than $10 \%$ of GDP by 2020 . In the next 10 years, China's sharing economy is expected to see 5 to 10 giant platform-based companies [13].

\subsubsection{Challenge}

In terms of business models or fields involved, most of China's early sharing economy platforms started from imitating foreign platforms. However, successful sharing economy platforms are not simply copying, but localizing innovation on the basis of imitation. All new things have growing pains, and the sharing economy is no exception. At home, the current challenges of the sharing economy are mainly the imperfect regulatory system. The current dominant economic and social management system is based on industrial economy and industrial mass production. It emphasizes centralized management, hierarchical management, regional and segmented management, mphasizing prior approval and access. The sharing economy based on network has the typical characteristics of network, cross-region and cross-industry. Rapid development of practice has made many systems increasingly inappropriate.

\subsection{The current business model of bike- sharing}

At present, the profit model of shared bikes at home and abroad is not very clear. The profit sources of domestic shared bikes are mainly divided into three ways. The first is rent, which is also the main source of profit. Mobile charges 1 yuan per half an hour; Ofo charges Rmb1 per hour; It is RMB 1 per half hour. Second, the source of profit in the form of deposit. Companies can make money from a pool of user deposits -- Rmb199 for Ofo and Rmb299 for Harrow and Rmb299 for Mobile. Third, sources of profit in the form of advertising flow. With large traffic and big data characteristics, shared bikes can make profits through advertising and other means by relying on their powerful user scale. The income source of foreign shared bikes is similar to the domestic situation, mainly from the deposit and rental fees. Lime Bike charges 1 US dollar per hour, and students pay half the price. Obie charges $\$ 35$ for a deposit and $\$ 0.70$ per half-hour [14]. In fact, none of these bike-sharing companies is making steady profits. Although the current user flow of bikesharing platform is considerable, due to low service price and high maintenance cost, its overall profitability is weak and it has the disadvantage of single mode. In addition, with the special management and deposit free, the profitability of this item is constantly weakened, and its business model is therefore confronted with great challenges. This also proves that the current value creation logic of shared bikes cannot adapt to the increasingly diversified network forms under the background of sharing economy. This paper holds that the realization of enterprise value should depend on the 
complex cooperation mechanism including enterprise, customer and other participants. The individual strategy of an enterprise should take its value network as a whole, organically combine individual strategy and overall strategy, and promote the transformation of enterprise from single product value thinking to network value thinking.

\subsection{The problem of risk management and profitability of business model of sharing economy}

According to the Annual Report on the Development of China's Sharing Economy (2021) released by the State Information Center, the market turnover of China's sharing economy in 2020 will be about $3,377.3$ billion yuan, with a year-on-year increase of about $2.9 \%$. There were about 830 million participants in the sharing economy, of which about 84 million were service providers, up about 7.7 percent year on year. It is not difficult to see from these data that the sharing economy has played a positive role in stabilizing employment and developing the economy, but in the process of its rapid development, there are also hidden risks [15].

\subsubsection{Risks brought by the behavior of resource suppliers and demanders}

The vast majority of sharing economy adopts the platform mode, and both parties establish trading relations only based on the platform information, which is very likely to cause moral hazard due to the improper behavior of traders. For example, the immoral or illegal behavior of resource suppliers will cause harm to the demanders. Similarly, the behavior of resource demanders in breach of contract also happens from time to time, such as overdue payment of clothing sharing rental, loss or damage of equipment or items configured in the short-term rental house.

\subsubsection{User privacy and information security risks}

In the platform model of sharing economy, both supply and demand must register their real names on the platform in order to conduct timely supervision. Such a large amount of personal real information, once the platform's network system is hacked or intentionally leaked for profit, will greatly damage the interests of users. For example, the increase of online registration and network access for online car hailing, including freight dealers, may increase the risk of personal information disclosure and security hidden danger.

\subsubsection{Trust risk of shared platform}

In the actual operation, most of the parties involved in the sharing economy establish a relationship with the network platform as a link, and their payment transactions have great instability. The platform provider may fail to pay the funds or deposits in time as agreed due to the bankruptcy of the enterprise due to business difficulties, thus causing damage to the interests of the transaction party. For example, the problem of refund of deposits for millions of Ofo sers has not been solved. In 2019, Sun, a junior at Tsinghua University's law school, applied to the Beijing No. 4 Intermediate People's Court to get his deposit back, but the application fee of 400 yuan was rejected. Sun's 99yuan deposit was not returned, but he lost 400 yuan [16]. This specific incident also reflects the lack of laws to protect the interests of consumers in the sharing economy.

\subsubsection{Risks caused by monopoly and unfair competition}

The fierce competition between different sharing economy platforms is often based on price war, which also brings the potential problem of industry monopoly. According to the data in May 2020, the monthly active number of Didi platform is as high as 54.39 million, 51.93 million more than the second place Shaoqi Taxhailing, and it has an absolute leading position in the online car-hailing market [17]. Moderate competition is conducive to the healthy development of the market and gives consumers more choices. Similarly, low price competition for market position will also directly affect the behavior of the supplier. For example, the "freight laborer" drivers who receive orders at a low price often hope to increase their income by paying their services. Once things go against their wishes, they will not be happy to speak badly of the user, or take detour to receive more orders in a limited time. For example, on the platform of goods laborer, users often complain that drivers temporarily increase prices, goods damage and other events that damage the interests of consumers are exposed. Analyzing the occurrence of these events, it is hard to say that the low-price strategy adopted by the platform in order to rapidly expand the user base is not one of the causes of this risk.

\section{DISCUSSION}

In view of the problems of the sharing economy mentioned above, the following will put forward the optimization countermeasures for the risk management and profitability of this model.

\subsection{Accelerate legislation}

In the practice of sharing economy, some companies are very anxious about the non-return and private possession of shared resources. In this regard, the government should learn to use the normative role of law. 


\subsubsection{Improve regulations}

The regulations should clarify the responsibility for the management of shared goods, punish those who destroy or privatize shared goods maliciously, and clarify the standard of deposit collection and the management method of deposit, so as to promote the standardized development of the sharing economy industry.

\subsubsection{Popularize legal knowledge}

It is necessary to popularize legal knowledge and guide the public to participate in the use of the sharing economy. Not only can the company force or prompt users to read the terms of use on the sign-up page, but it can also introduce and demonstrate the rules to users through short, fun videos. In addition, vivid and interesting posters can be posted in crowded places such as subway stations and bus stations. For example, cartoons can be used to introduce the use of procedures and rules, or to satirize violations.

\subsubsection{Ensure law enforcement}

Some measures can be taken to ensure the enforcement of the law and provide a guarantee for promoting the development of the sharing economy. For instance, each industry can set up a trade association to urge enterprises in the same industry to comply with relevant regulations to prevent vicious competition by lowering the requirements on users. A credit rating system may be set up for customers. Points will be deducted for users who violate the rules of sharing economy, and points can be added for users who maintain the rules and keep good records. The government should improve supporting infrastructure and set up signs to guide the prosperous areas. For example, set up the suggested parking area for shared bikes or shared cars, and set up signs in the bike lanes [18].

\subsection{Establish safe harbour for data transfers}

The leakage of real-name authentication information is also a serious problem that hinders the development of the sharing economy. To address the damage to the reputation of the sharing economy caused by information leaks, companies can take proactive measures to identify, continuously monitor and address potential threats, including physical and technical security measures such as firewalls and encryption. What's more, companies should ensure that personnel handling personal data are trained to identify and minimize the risk of data leakage due to internal failures. The choice of intermediaries and service providers should be very careful because they may be the link of information leakage. Check that those involved in the collection and processing of personal data have good security measures in place, including virus protection, data backup, security breach notification, and restrictions on subsequent processing. Finally, companies also need to prepare for security breaches so that they can act quickly in the event of a data breach to ensure the continued availability of their platforms, thereby mitigating he impact of the breach and minimizing the impact of negative publicity [19].

\subsection{Formulate anti-monopoly laws and promote competition}

On the one hand, the government should accelerate the formulation and promulgation of relevant laws and regulations in line with the current social and economic anti-monopoly, and further improve industrial management methods and strengthen supervision. At the same time, the market should also be opened up to promote fair competition and a win-win situation among various service models. On the other hand, in view of the continuous development of innovation, new technologies and new service models in the Internet age will continue to emerge, and new enterprises and new service models may break old monopolies.Therefore, enterprises with monopoly ability should have selfdiscipline and foresight, explore new innovative profit points, maintain reasonable prices and high-quality services, and stabilize the original customer base [20]. However, at the same time, the government also needs to monitor emerging sharing models to reduce the overprovision of shared services, which is happening in many sectors as companies compete for market share [21].

\subsection{Adopt Blockchain Technology}

A blockchain-based solution would be a promising way to simultaneously address some of the disadvantages of the sharing economy analyzed above. Only by rewriting the technical code and eliminating the shelter can we really solve the essential problem of the sharing economy and avoid the potential negative possibilities Satoshi Nakamoto first proposed blockchain in an article about Bitcoin in 2008 [22]. It has gradually attracted the attention of government departments, capital markets and other industries, and is considered to be the most likely innovation to rebuild the world after the mobile Internet. At present, it has been used in finance, medical care, insurance, education and other fields. Blockchain bundles data into blocks in chronological order, connects them in chains, and ensures that all data cannot be forged or tampered with through asymmetric cryptography. Therefore, it has the technical characteristics of decentralization, traceability, non-tampering, collective maintenance and consensus trust, and can effectively realize peer-to-peer transactions, thus ideally solving the problems of 
information leakage, trust risk, private occupation and so on in the sharing economy [23].

\section{CONCLUSION}

In summary, the current challenge of the sharing economy is mainly the imperfect regulatory system. Take the bike-sharing industry as an example. In fact, few of the major bike-sharing companies have been able to make steady profits for the time being. Although the current number of users is considerable, the overall profitability is weak due to low service prices and high maintenance costs. What's more, there are hidden risks in the process of rapid development of the sharing economy. It is mainly divided into four categories of risks: the risks caused by the unethical behavior of resource suppliers and demanders, the risks of user privacy and information security, the risks of trust between sharing platforms and consumers, and the risks caused by monopoly and unfair competition. Therefore, the government should first strengthen legislation to regulate suppliers and demanders' behavior and then improve the anti-monopoly law and promote competition to make the market more flexible and standardized. The company itself should also strengthen the protection of customer information, flexibly use the blockchain model to establish an open and transparent shared database, and at the same time learn to explore new innovative profit points to avoid being eliminated by the market.

The materials used in this study are mainly from economic journals as secondary materials. The secondary data have some limitations. For example, the study only uses the existing research results of the sharing economy model in the current market for analysis. These results do not fully fit our research direction. The article mainly studies the risk control and profitability analysis of the sharing economy. In that case,we can design experiments, get the research results of the study's research experiments, and put them in the results of the demonstration. Our team can add experimental controls to experiments. For example, the profit analysis of Didi Taxi in China and the profit model of Uber are compared and analyzed based on national conditions.

\section{REFERENCES}

[1] A.Akhmedova, A. Manresa, D. Escobar, A.Bikfalvi, Service quality in the sharing economy: A review and research agenda, in: International Journal of Consumer Studies, vol.45, 2021, pp. 889-910. DOI: https://doi.org/10.1111/ijcs.12680

[2] K.Taeuscher, J.Kietzmann,Learning from Failures in the Sharing Economy,in: MIS Quarterly Executive,vol.16,2017, pp. 253-263.
[3] The Sharing Economy,in:PricewaterhouseCoopers. https:/www.pwc.fr/fr/assets/fifiles/pdf/2015/05/pw c_etude_sharing_economy.pdf

[4] J.H.Hong, B.C. Kim, K.S.Park, Optimal risk management for the sharing economy with stranger danger and service quality, in:European Journal of Operational Research, Elsevier, vol. 279, 2019, pp. 1024-1035.DOI:

https://doi.org/10.1016/j.ejor.2019.06.020

[5] The "sharing" economy:issues facing platforms, participants \& regulators. A federal trade commission staff report (November 2016), in: Federal Trade Commission. https://www.ftc.gov/reports/sharing-economyissues-facing-platforms-participants-regulatorsfederal-trade-commission

[6] China's Annual Report on Development of Sharing Economy, in:The State Information Center.

$$
\begin{aligned}
& \text { http://www.sic.gov.cn/archiver/SIC/UpFile/Files/ } \\
& \text { Default/20190301115908284438.pdf }
\end{aligned}
$$

[7] M.Hossain, Sharing Economy: A Comprehensive Literature Review,in:International Journal of Hospitality Management,vol. 87. DOI:https://doi.org/10.1016/j.ijhm.2020.102470.

[8] M.Cheng,Sharing economy: A review and agenda for future research,in:International Journal of Hospitality Management,vol.57, 2016, pp. 60-70. DOI:https://doi.org/10.1016/j.ijhm.2016.06.003.

[9] V.Kumar,A.Lahiri,O.B.Dogan, A strategic framework for a profitable business model in the sharing economy,in:Industrial Marketing Management, vol. 69, 2018, pp. 147160.DOI:https://doi.org/10.1016/j.indmarman.2017 08.021

[10] MBA think tank Encyclopedia, information from https://wiki.mbalib.com/zhtw $\%$ E6\%A1\%88\%E4\%BE $\% 8 B \%$ E7\%A0\%94\%E $7 \% \mathrm{~A} 9 \% \mathrm{~B} 6 \% \mathrm{E} 6 \% \mathrm{~B} 3 \% 95$

[11] Cotta Scholarship, information from https://www.sciping.com/14833.html

[12] Wikipedia, information from https://en.wikipedia.org/wiki/Qualitative_comparat ive analysis

[13] Problems existing in the development of shared bikes in China and countermeasures and suggestions, Chinaqking, http://www.chinaqking.com/yc/2019/1639463.html

[14] M. Kaiyang, Y. Lijing, [J]. Urban Tribune, 2017, 38 (4): 103-108. 
[15] Risks and regulations in the development of sharing economy, Finance Sina, https://finance.sina.com.cn/tech/2021-03-10/docikkntiak7560689.shtml

[16] Research and analysis on the status quo of sharing economy,

lwlm.com, http://lwlm.com/Economy/201707/852550.htm

[17] Sharing economy opens' window of opportunity, Central People's Government of the People's Republic of China, http:/www.gov.cn/xinwen/201606/16/content_5082669.htm

[18] Z. Li, The rise and challenge of sharing economyAnalysis from an economic and legal perspective, in: Contemporary Economic Management, vol. 38, 2016.

[19] Sharing economy: Practical steps to address data privacy and cyber security risks, Osborne Clarke, https://www.osborneclarke.com/insights/sharingeconomy-practical-steps-to-address-data-privacyand-cyber-security-risks/

[20] Ubernomics: platform monopolies \& how to fix them, Rufus Pollock, https://rufuspollock.com/ubernomics

[21] Z. Mi, D.M. Coffman, The sharing economy promotes sustainable societies, in: Nature Communications, vol. 10, 2019, DOI: https://doi.org/10.1038/s41467-019-09260-4

[22] S. Nakamoto, Bitcoin: a peer-to-peer electronic cash system, DOI: https://bitcoin.org/bitcoin.pdf

[23] Y. Li, Optimization mode of sharing economy for data defects based on blockchain, in: International Conference on Advanced Electrical, Mechatronics and Computer Engineering, 2019, pp. 231-235. DOI: https://www.dpiproceedings.com/index.php/dtetr/article/viewFile/2 9517/28491 